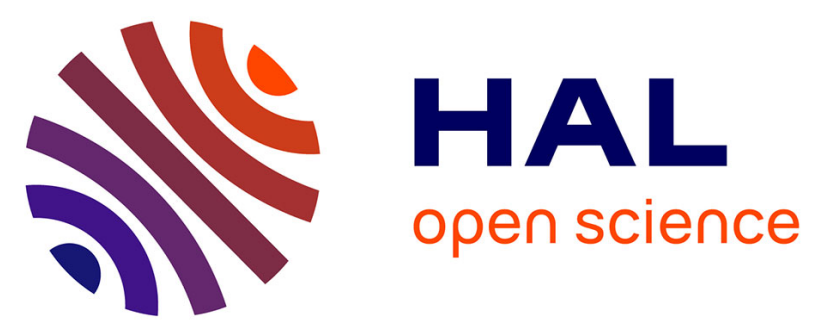

\title{
Interventions to increase access to STI services: A study of England's 'High Impact Changes' across three central London clinics
}

\author{
Anatole S Menon-Johansson, Charlotte Cohen, Rachael Jones, Nneka \\ Nwokolo, Alan Mcowan, Simon E Barton, Sundhiya Mandalia, Ann K Sullivan
}

\section{To cite this version:}

Anatole S Menon-Johansson, Charlotte Cohen, Rachael Jones, Nneka Nwokolo, Alan Mcowan, et al.. Interventions to increase access to STI services: A study of England's 'High Impact Changes' across three central London clinics. Sexually Transmitted Infections, 2010, 86 (7), pp.540. 10.1136/sti.2009.039826 . hal-00557460

\section{HAL Id: hal-00557460 \\ https://hal.science/hal-00557460}

Submitted on 19 Jan 2011

HAL is a multi-disciplinary open access archive for the deposit and dissemination of scientific research documents, whether they are published or not. The documents may come from teaching and research institutions in France or abroad, or from public or private research centers.
L'archive ouverte pluridisciplinaire HAL, est destinée au dépôt et à la diffusion de documents scientifiques de niveau recherche, publiés ou non, émanant des établissements d'enseignement et de recherche français ou étrangers, des laboratoires publics ou privés. 


\section{Interventions to increase access to STI services: A study of England's 'High Impact Changes' across three central}

\section{London clinics}

Menon-Johansson A.S. , C., Cohen C.E., Jones R., Nwokolo N., McOwan A., Barton S.E., Mandalia, S. \& Sullivan A.K.

Chelsea and Westminster Hospital NHS Foundation Trust

369 Fulham Road

London

SW10 9NH

*Corresponding author: a.menon-johansson@nhs.net

Department of Genitourinary Medicine

Harrison Wing

2nd Floor - Lambeth Wing

St. Thomas' Hospital

London SE1 7EH

United Kingdom

Keywords: Health Service Research; Policy; Public Health; Screening; STD services

Running title: High impact changes 


\section{Abstract}

\section{Background}

Increasing access to sexual health services is a key objective for the Department of Health (DH) in England and Wales. In 2006 the DH published ten high impact changes (HICs) designed to enhance 48-hour access to genitourinary medicine services. However, there is limited evidence on the effectiveness of the proposed interventions. We therefore evaluated the implementation of five HICs in three sexual health clinics over four years. These HICs included a text message results service, nurse-delivered asymptomatic service, clinic refurbishment, a centralized booking service and an electronic appointment system.

\section{Methods}

The impact of HICs was evaluated by measuring clinical activity, number of sexual health screens performed and patients seen within 48 hours. These data were obtained from the clinic database, KC60 coding returns and Health Protection Agency waiting time surveys, respectively.

\section{Results}

The median number of new patients seen per month increased from 3635 to 4263 following the implementation of the five high impact changes. The follow-up to new patient ratio fell from 0.67 to 0.21 during this study. The biggest fall corresponded with a rise in patients receiving results by text message, from zero to $40 \%$. Only the centralized booking service was associated with a significant increase in the number of new patients seen.

\section{Discussion}

Providing results by text message was associated with a reduced number of follow-up patients whilst implementation of a centralized booking service coincided with a significant increase in patient access. Further research is required to evaluate the relative importance of the other HICs.

$($ Word count $=250)$ 


\section{Introduction}

The major providers of sexual health services in the UK are specialist genitourinary medicine (GUM) clinics. In 2007, an estimated one million patients were seen in UK GUM clinics ${ }^{1}$ where they received testing, specialist diagnostic and treatment services, sexual health advice and contact tracing. Rapid access to services is essential to reduce sexually transmitted infection (STI) transmission, complications and facilitate epidemic control ${ }^{2}$. However, in recent years, timely access for patients has been suboptimal ${ }^{3-6}$.

In 2006, a performance indicator was introduced by the Department of Health for England and Wales where all patients attending GUM clinic services should be offered an appointment to be seen within 48 hours by March 2008. In addition, all regions of England and Wales were asked to plan to see $95 \%$ of GUM patients within 48 hours by this same date. In response to this, best practice guidance was developed to increase access and STI testing ${ }^{7}$. This guidance defined four themes with ten high impact changes (HICs) to achieve GUM access in 48-hours (Table 1). The evidence base to support the proposed HICs ranged from case reports to the citation of research in peer-reviewed journals.

The Chelsea \& Westminster Hospital NHS Foundation Trust has three GUM clinics operating across three separate National Health Service units (primary care trusts) that are involved in the commissioning of healthcare services in the central North West sector of London. In 2004 these clinics served a local population of 368,000 adults plus commuters. Since that year, five of the seven HICs relating to 'maximizing the use of existing resources' and 'improving efficiency' were introduced across all three clinical sites. These HICs were, in chronological order, a text message results service (TMRS), nurse-delivered asymptomatic service (NDAS), the refurbishment of one 
GUM clinic, a centralized booking service (CBS) and the introduction of an electronic appointment system (EAS) (Table 1).

In March 2008, the three clinics met the access target to offer an appointment within 48 hours; however, it is not clear which HICs were effective and to what extent. We therefore investigated the effect of introducing HICs on service provision across the study clinics (SCs). 


\section{Methods}

The five HICs were introduced over a four-year period between 2004 and 2007. The number of new patients, follow-up patients and sexual health screens for each month from January 2004 to January 2008 were determined for the SCs. Korner (KC60) codes are mandatory codes of clinical activity that are submitted each quarter as aggregate figures by reporting GUM clinics to the Health Protection Agency (HPA). The S1 code represents a sexual health screen (testing for Chlamydia trachomatis and Neisseria gonorrhoeae with or without a serological test for syphilis test) without an HIV test. The S2 code represents a sexual health screen that includes an HIV test. For this study, a sexual health screen was defined by the attribution of either the S1 or S2 KC60 codes to a particular patient episode. The percentage of patients seen in 48 hours by the three clinics was determined from nine Health Protection Agency GUM waiting time audits from May 2005 to May 2007.

The TMRS was introduced in March 2004 and the number of texts sent monthly was obtained from the system's activity log (Mikkom, Windsor, UK). The NDAS started in May 2005 and this activity was captured by an additional code specific to SCs that was recorded for each patient alongside the KC60 coding. The refurbishment of one clinic took place between November 2005 and February 2006. All appointment requests were made via the CBS from March 2006 and the EAS was introduced in October 2006; the usage of both systems was determined from monthly activity reports.

The percentage of patients receiving TMRS, NDAS and EAS was obtained from the number of patients using each HIC divided by the total clinical activity. The CBS made appointments for 85 percent of the clinic slots available; the remainder of the patients were seen without appointments as "walk-ins". 


\section{Statistical analysis}

Using the two months prior to the introduction of the text message result service as a baseline, we fitted an autoregressive regression model to the percentage change in the number of sexual health screens and used the coefficient of determination to quantify the strength of the variations. Since the data contained a series of autocorrelated observations this was accounted for by using an autoregressive regression model that assessed the degree of accuracy to which a sexual health screen attendance could be predicted by stable seasonal variation. The data are presented pictorially (Figure 1) as percentage changes in number of sexual health screens since baseline when text the messaging service had not been introduced.

The relationship between the nine one-week HPA GUM waiting time surveys and the corresponding number of new patients and sexual health screens seen in each clinic was determined using linear regression analysis. The number of sexual health screens (KC60 codes S1 or S2) for each GUM clinics in London for each year from 2004 to 2007, excluding the SC and two other clinics that only provided partial data, were obtained from the HPA (Stephen Duffel, Health Protection Agency, personal communication). These results were used to put the changes determined from this analysis into context. 


\section{Results}

\section{The number of patients seen, and follow-up to new ratios}

The median number of new patients seen and sexual health screens in parenthesis per month increased from a baseline of 3635 (2283) to 4263 (3214), in 2004 and 2007, respectively, following the implementation of the five HICs (see Figure \& Table). Over this period the follow-up to new patient ratio decreased from 0.63 to 0.23 and the median percentage of new clinic attendees having a sexual health screen increased from $63 \%$ to $75 \%$ for the years 2004 and 2007, respectively. Prior to starting NDAS, CBS and EAS the follow-up to new patient ratio was $0.37,0.37$ and 0.34 , respectively.

The presence of each HIC and the percentage change of sexual health screens performed over four years across the SCs are shown in Figure 1. After one year (March 2004 to April 2005), 40\% of patients received their results by text message. The number of sexual health screens increased by $10 \%$ after the first year of TMRS and a further $20 \%$ following the introduction of CBS. Compared to $2004 / 2005$, the $2006 / 2007$ period showed a significant increase in the number of sexual health screens $(\mathrm{p}<0.001)$.

A three-month clinic refurbishment at the end of 2005 temporarily reduced that clinic's capacity by two thirds. When the three clinics were analyzed separately, the percentage increase in the median number of new patients [sexual health screens] from 2004 to 2007 was $5 \%$ [18\%] for the refurbished clinic compared with a $12 \%$ [61\%] and 51\% [56\%] increase for the other two clinics.

The CBS commenced in the first week of March 2006 and this service was able to book up to $85 \%$ of clinic appointments across the three SCs. The EAS was introduced in October 2006 and 5\% of appointments were made using this service in the first month. The number of appointments made by EAS rose to $15.5 \%$ by then end of the study in January 2008 . 


\section{Rapid access (seen within 48 hours)}

The percentage of patients seen in 48 hours for the SCs was 30, 45 and 75 percent for the month of May in 2005, 2006 and 2007, respectively. During nine one-week HPA GUM waiting time surveys, the number of new patients and sexual health screens correlated significantly with the percentage of patients seen within 48 hours $(r=0.69, \mathrm{p}<0.05$ and $\mathrm{r}=0.88, \mathrm{p}<0.01$, respectively).

\section{Comparison with other London GUM clinics}

In 2004 the SCs performed 734 sexual health screens per clinic per month compared to a London GUM clinic average of 532. Despite the higher throughput at baseline, the SCs had a greater year on year increase in the number of sexual health screens over time. The annual increase from a 2004 baseline for the other 29 GUM London clinics was 6.4, 9.1 and 19.5\% for 2005, 2006 and 2007, respectively, whilst it was 1.6, 22.6 and $44.4 \%$ in the SCs for the same three years, respectively. 


\section{Discussion}

The aim of the ten High Impact Changes was to improve access, measured by the number of patients offered an appointment and those seen within 48 hours. We observed an improvement in access over four years following the introduction of five of the ten HICs. The follow-up to new ratio patient fell predominantly in first 17 months of this analysis when the number of patients receiving their results by text message rose from zero to $40 \%$.

The initial rise in the number of new patients having a sexual health screen in 2004 in this analysis may be solely due to the fall in the number of follow-up patients attending clinic releasing staff time and resources, and thereby increasing capacity. Griffiths et al ${ }^{8}$ identified 40 potential factors that could reduce the number of follow-up patients attending clinic. The SCs introduced a number of these factors in the first year of this analysis; however, the biggest change at this time was the introduction of the text message result service. Griffiths et al demonstrated that the follow-up to new patient ratio fell over two years from 0.80 to 0.61 by the beginning of 2005 in the twelve clinics studied. A similar large fall in the ratio was seen in the SC (0.61 to 0.37$)$ and this corresponded with a $10 \%$ increase in the number of sexual health screens.

The most effective change to increase the number of sexual health screens appears to have been the introduction of the Centralized Booking Service. This change allowed the three GUM clinics to begin to match capacity with patient demand. The increased numbers of sexual health screens consisted predominantly of new patients attending the service. Unfortunately, no internal control exists to test how the service would have changed without the introduction of CBS. However, since only the SCs introduced a CBS at this time a direct comparison was made with 29 other London GUM clinics. The numbers of sexual health screens performed per clinic per month was higher in the SCs in 2004 and the percentage increase in 2006/7 was two times greater than their London counterparts, despite starting from a higher baseline. 
Prior to the introduction of CBS, one quarter of patients were seen by the NDAS and nearly one half of patients used the TMRS (see Table 1). The impact of these changes on the percent change in the number of sexual health screens can possibly be discerned from Figure 1; unfortunately, the impact of refurbishing one clinic obscures the possibility of demonstrating a stepwise change. After CBS had been operational for one year, the number of patients using TMRS doubled as a result of making it the default option. The small change is noted in the percent change in the number of sexual health screens at this time also coincides with a doubling of the number of patients using the EAS. Consequently, the significant and sustained stepwise change following the introduction of CBS will have also been complemented by the other HICs.

The efficiency of CBS for patients has been clear, not only for ease of contacting the service but also in identifying a free appointment across the three clinics. Many examples in industry have demonstrated the benefit and impact of investing in a process improvement and then achieving an economy of scale ${ }^{9}$. It is likely that the fall in the number of follow-up patients and the introduction of CBS have had the biggest impact on the percent increase in the number of sexual health screens.

Expanding CBS further to include additional GUM clinics and other providers of sexual and reproductive health services may further benefit patients and maximise service utilization. However, it is not clear what would be the optimum number and range of services that could be supported by the CBS. In the future, sub-analyses of the number of sexual health screens by risk group, age, primary care trust of residence and ethnicity will allow us to understand utilisation of the service more clearly.

At the beginning of 2008 only $15.5 \%$ of appointments were booked via the EAS despite a qualitative analysis of this service indicating high levels of patient satisfaction ${ }^{10}$. Similarly, when 
the text message result service was first evaluated at six months, projections of time and cost savings were made based on a predicted $90 \%$ of all results being provided by this service ${ }^{11}$. However, during the last six months of 2007 only $77 \%$ of results were sent by text. It is possible that increased uptake of this system would improve with further promotion to patients; however, it is essential to explore any barriers that might deter patients from receiving their results by text message.

Clinic refurbishment had a significant negative impact on the number of sexual health screens that could be performed during the three months of renovations. The quality of the clinic environment definitely increased following this work as shown by patient and staff feedback (Sullivan, personal communication) but this did not produce a significant increase in the number of sexual health screens performed. It may be that the refurbished clinic was running close to capacity prior to the refurbishment; consequently, the changes resulted in only a small increase in the number of additional people screened. Furthermore the refurbishment focused mainly on improving the clinic environment and patient flow rather than increasing physical capacity of the clinic.

\section{Limitations}

In this analysis there a number of limitations that make it difficult to provide clear answers regarding the relative importance of each HIC. Firstly, this ecological study only looks at five HICs. It may be that other HICs or certain HIC combinations are more effective at increasing access to GUM clinics. This study was limited mainly to those HICs in the theme of maximising the use of existing resources to increase capacity. Secondly, the lag time to introduce individuals HICs, the probable impact lag time and the co-incident implementation of multiple HICs complicates this analysis. Even though we have adjusted for the relative contribution of each HIC, and the analysis appears to support CBS as the predominant factor in the stepwise change in 2006, 
there may be synergism that we are unable to detect because we were unable to clearly separate the introduction of these HICs.

In this analysis, the NDAS was not associated with an increase in the number of sexual health screens. However, this new service was allied with improvements in nurse training, patient streaming and urine nucleic acid amplification testing of asymptomatic women being introduced across the three clinics during this time period, all at differential rates. It may be that the benefit of all these changes was staggered with resultant blunting of the effect that was only realized following the introduction of CBS. Thirdly, even though the follow-up to new ratio was stable during the introduction of the HICs there may be some delay in the impact of the ratio change on the percent increase in the number of sexual health screens. Fourthly, the current clinical KC60 coding system makes it difficult to distinguish clearly the precise services delivered to each patient beyond sexual health screening. One quarter of new patients were not coded as having a sexual health screen; instead these individuals represent tertiary referrals, HIV care transfers or patients who received a range of services such as HIV testing, diagnosis and treatment of anogenital warts, dermatoses and the provision of contraception that are not captured by the current KC60 service codes.

An upgraded KC60 coding system will allow more detail to be captured, plus its extension to community providers will facilitate the collection of clearer data in the future. Fifthly, the HPA GUM waiting time audits only sampled respondents for a one-week period of time and an earlier study reported that the accuracy of patient-reported waiting times was overall only $52 \%{ }^{12}$. The weak correlation with the number of new patients and sexual health screens performed may reflect both the quality of this data and the small number of audits taken over this four-year period. Finally, it is essential to recognise that this analysis has focussed on process measures and not on concrete outcomes such as diagnoses, treatment and partner notification. 
Subsequent to this analysis, a mandatory GUM Access Monthly Monitoring system has been introduced that makes it possible to capture waiting time data for the attendance of each patient. Future analysis of GUM access will benefit greatly from this high quality data. Finally, clinics are heterogeneous and the average of the 29 London clinics that report to the HPA includes both smaller peripheral and large central clinics that differ in their staff numbers, expertise and range of services. Subsequently, future analyses would benefit from matching clinics by patient numbers, services and working time equivalent staff numbers and competencies so that HICs can be more clearly evaluated between clinics.

The 48-hour target has the potential to benefit both individual and public health. To achieve and sustain this target it is important that successful, evidence-based HICs are implemented and evaluated carefully. A future challenge will be to incorporate outcomes as 'quality of service' targets so that the pool of disease in the community can be addressed effectively. 
Word count: 2881

\section{Acknowledgements}

We would like to thank Stephen Duffel at the Health Protection Agency for providing the aggregate London data on sexual health screens.

\section{Conflict of interest}

ASM-J and AKS conceived and developed the clinical algorithm in the EAS and with Mikkom (www.mikkom.com) share the intellectual property rights for the 'eTriage' product.

\section{Authors' contributions}

ASM-J conceived, designed and wrote the paper, AKS contributed to the design, SM provided statistical analysis, AKS, CEC, RJ, NN, AM and SEB reviewed and edited the manuscript. 


\section{Key messages}

- A text message result service reduced unnecessary patient follow-up attendances and increased the percentage of patients having a sexual health screen by $10 \%$

- A centralized booking service was the most effective high impact change introduced and in this study increased the percentage of patients having a sexual health screen by a further $20 \%$

- Further detailed analysis across a range providers is required to determine the importance of all the proposed high impact changes

The Corresponding Author has the right to grant on behalf of all authors and does grant on behalf of all authors, an exclusive licence (or non exclusive for government employees) on a worldwide basis to the BMJ Publishing Group Ltd to permit this article (if accepted) to be published in STI and any other BMJPGL products and sub-licences such use and exploit all subsidiary rights, as set out in our licence http://group.bmj.com/products/journals/instructionsfor-authors/licence-forms. 
Table 1

\begin{tabular}{|c|c|c|c|c|c|c|c|c|}
\hline \multicolumn{9}{|c|}{ Department of Health's 10 High Impact Changes $^{7}$} \\
\hline \multirow[t]{2}{*}{ Theme } & \multirow[t]{2}{*}{$\begin{array}{c}\text { High Impact } \\
\text { Change }\end{array}$} & \multirow[t]{2}{*}{$\begin{array}{l}\text { Change } \\
\text { implemented } \\
\text { [Abbreviation] } \\
\text { Description }\end{array}$} & \multirow[t]{2}{*}{\begin{tabular}{|c|} 
Date \\
introduced
\end{tabular}} & \multicolumn{5}{|c|}{$\begin{array}{l}\text { Percentage of patients having a } \\
\text { sexual health screen who used a } \\
\text { high impact change in January } \\
\text { of each year }\end{array}$} \\
\hline & & & & 2004 & 2005 & 2006 & 2007 & 2008 \\
\hline $\begin{array}{l}\text { Identify how } \\
\text { much capacity } \\
\text { you need to } \\
\text { meet the } \\
\text { access target }\end{array}$ & $\begin{array}{l}\text { 1: Measure } \\
\text { demand and } \\
\text { capacity across } \\
\text { the local health } \\
\text { economy }\end{array}$ & & & & & & & \\
\hline & $\begin{array}{l}\text { 2: Undertake a } \\
\text { process } \\
\text { improvement } \\
\text { project to inform } \\
\text { service redesign }\end{array}$ & & & & & & & \\
\hline & $\begin{array}{l}\text { 3: Analyse and } \\
\text { improve } \\
\text { utilisation of the } \\
\text { multidisciplinary } \\
\text { team in GUM }\end{array}$ & $\begin{array}{l}\text { Nurse- } \\
\text { delivered } \\
\text { asymptomatic } \\
\text { service } \\
\text { [NDAS] } \\
\text { Asymptomatic } \\
\text { patients were } \\
\text { streamed to } \\
\text { and then }\end{array}$ & May 2005 & 0 & 0 & 25 & 36 & 34 \\
\hline
\end{tabular}




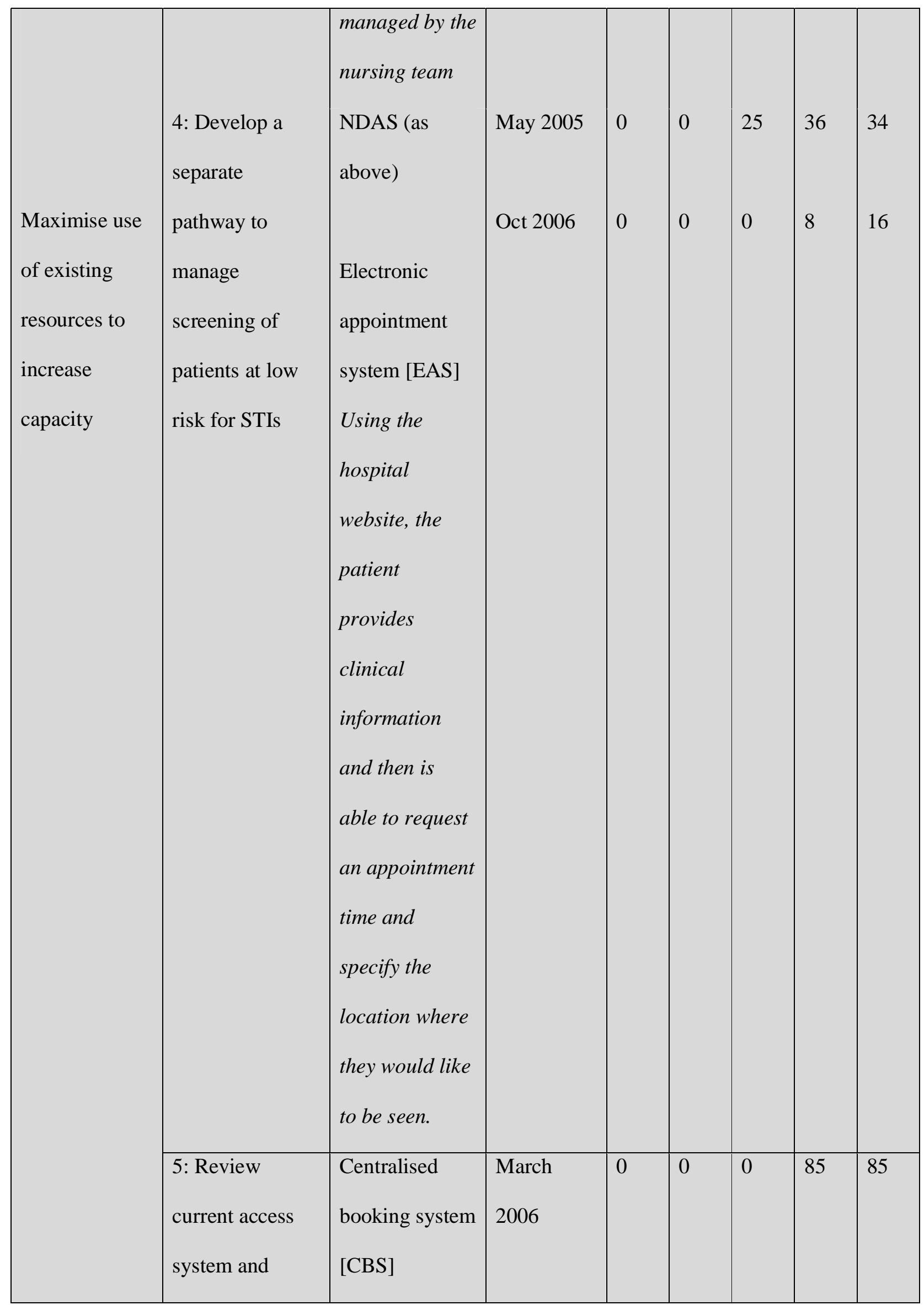




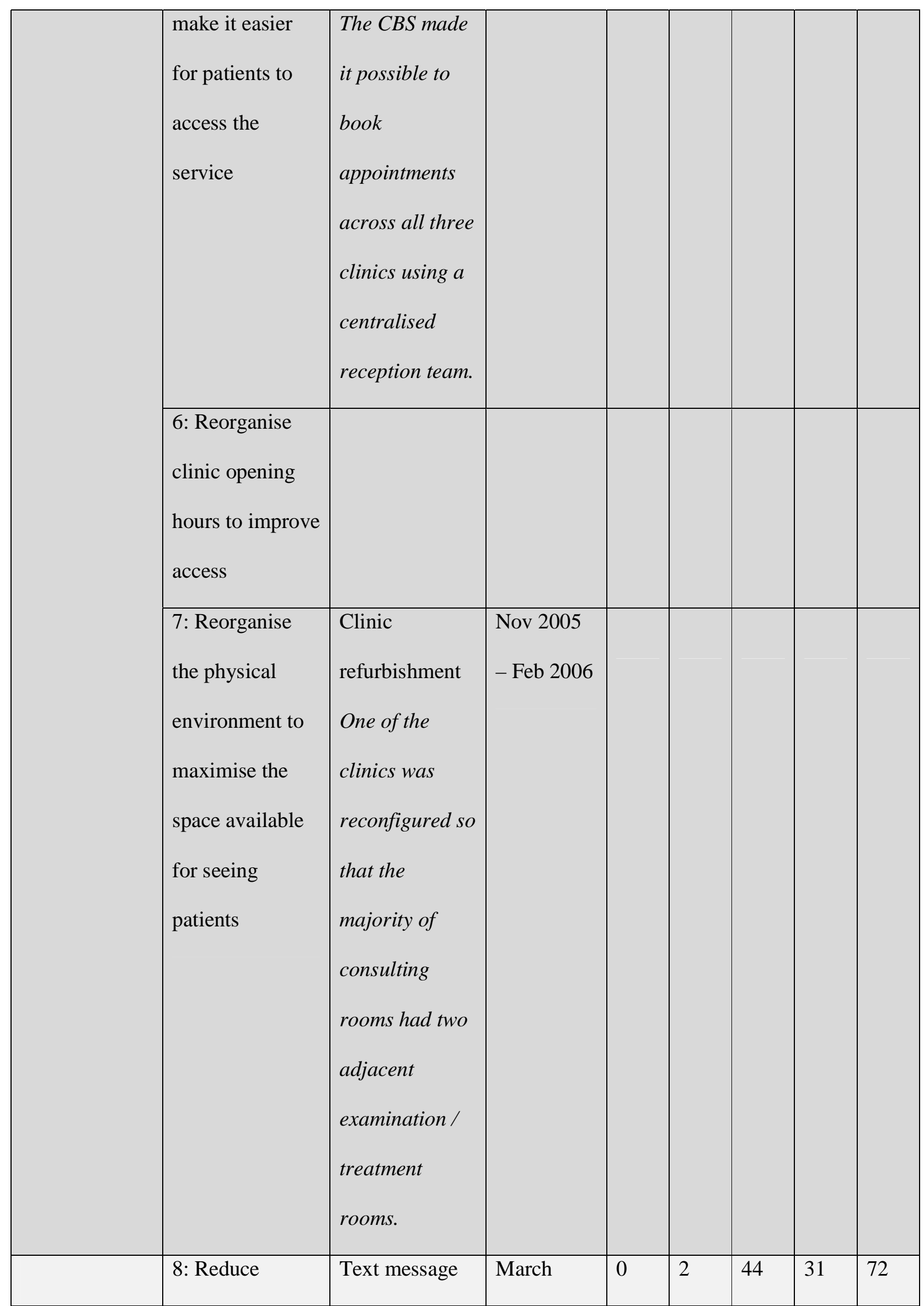




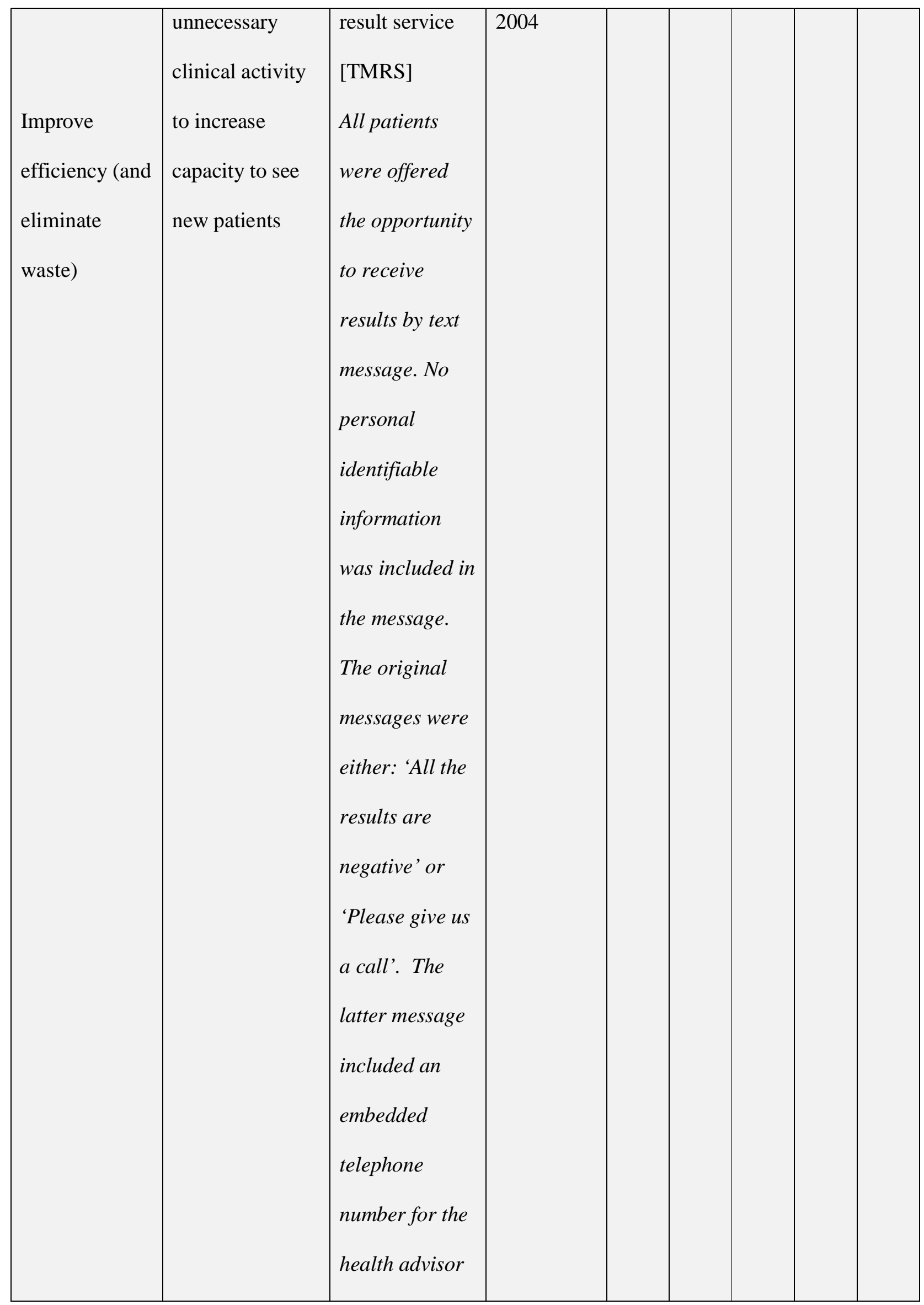




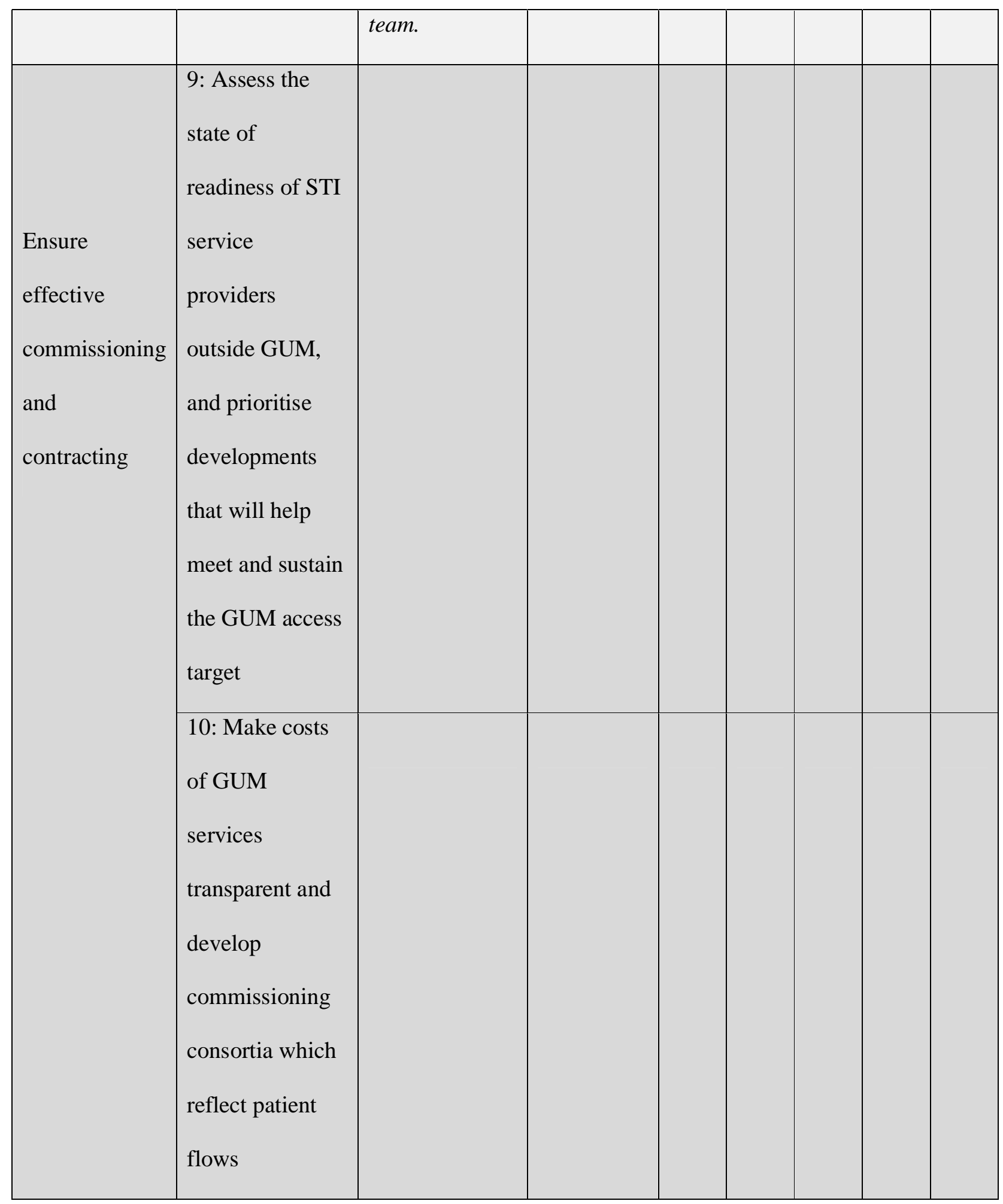




\section{Legends}

\section{$\underline{\text { Figure } 1}$}

Figure 1 shows the percentage change in number of sexual health screens over time since the introduction of the text message result service. The introduction of each High Impact Change is indicated by text the figure.

\section{$\underline{\text { Table } 1}$}

Table 1 shows the Department of Health's 10 High Impact Changes to enable 48-hour access to GUM clinics and the corresponding changes made in the study clinics. 


\section{References}

1. The UK Collaborative Group for HIV and STI Surveillance. Testing Times. HIV and other Sexually Transmitted Infections in the United Kingdom: 2007. London: Health Protection Agency, Centre for Infections. November 2007.

2. Aral SO, Roegner R. Mathematical modeling as a tool in STD prevention and control: a decade of progress, a millennium of opportunities. Sex Transm Dis 2000;27(10):556-7.

3. Djuretic T, Catchpole M, Bingham JS et al. Genitourinary medicine services in the United Kingdom are failing to meet current demand. Int J STD AIDS 2001;12(9):571-2.

4. Foley E, Patel R, Green N et al. Access to genitourinary medicine clinics in the United Kingdom. Sex Transm Infect. 2001;77(1):12-4.

5. Mercer CH, Sutcliffe L, Johnson AM, et al. How much do delayed healthcare seeking, delayed care provision, and diversion from primary care contribute to the transmission of STIs? Sex Transm Infect. 2007;83(5):400-5.

6. Clarke J, Christodoulides H, Taylor Y. Supply and demand: estimating the real need for care while meeting the 48 hour waiting time target in a genitourinary medicine clinic by a closed appointment system. Sex Transm Infect.2006;82(1):45-8.

7. Department of Health. 10 High Impact Changes for Genitourinary Medicine 48-hour Access. 277527/10 DH Publications. (accessed $17^{\text {th }}$ March, 2010) http://www.dh.gov.uk/prod_consum_dh/groups/dh_digitalassets/@dh/@en/documents/digitalasset/ dh_062814.pdf, 2006.

8. Griffiths V, Ahmed-Jushuf I. Releasing capacity in sexual health through modernization. Int J STD AIDS. 2007;18(5):299-304.

9. Baumol WJ, Blinder AS. Economics : principles and policy. 10th ed. Mason, Ohio: Thomson/South-Western, 2006.

10. Jones R, Menon-Johansson A, Waters AM et al. eTriage - a novel, web-based triage and booking service: enabling timely access to sexual health clinics. Int J STD AIDS. 2010;1:30-33.

11. Menon-Johansson AS, McNaught F, Mandalia S et al. Texting decreases the time to treatment for genital Chlamydia trachomatis infection. Sex Transm Infect. 2006;82(1):49-51.

12. Rutland E, Rowberry C, Patel R et al. Measuring access: how accurate are patient-reported waiting times? Sex Transm Infect. 2008;84(1):70-1. 


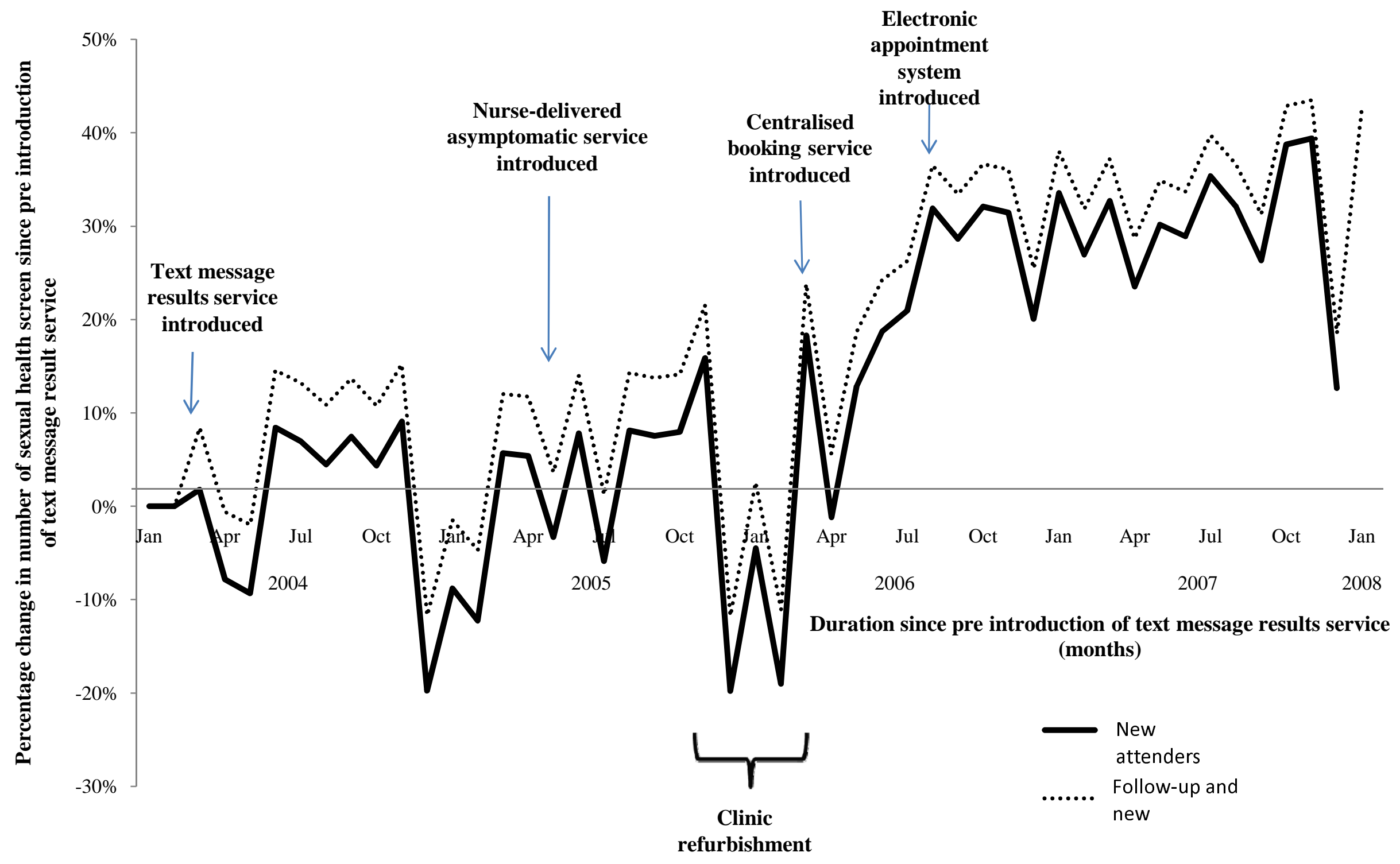

